\title{
Sensitive periods for the effect of childhood interpersonal violence on psychiatric disorder onset among adolescents
}

\author{
Erin C. Dunn, Yan Wang, Jenny Tse, Katie A. McLaughlin, Garrett Fitzmaurice, Stephen E. Gilman \\ and Ezra S. Susser
}

\section{Background}

Although childhood adversity is a strong determinant of psychopathology, it remains unclear whether there are 'sensitive periods' when a first episode of adversity is most harmful.

\begin{abstract}
Aims
To examine whether variation in the developmental timing of a first episode of interpersonal violence (up to age 18) associates with risk for psychopathology.

\section{Method}

Using cross-sectional data, we examined the association between age at first exposure to four types of interpersonal violence (physical abuse by parents, physical abuse by others, rape, and sexual assault/molestation) and onset of four classes of DSM-IV disorders (distress, fear, behaviour, substance use) ( $n=9984)$. Age at exposure was defined as: early childhood (ages 0-5), middle childhood (ages 6-10) and adolescence (ages 11-18).
\end{abstract}

\section{Results}

Exposure to interpersonal violence at any age period about doubled the risk of a psychiatric disorder (odds ratios
$(\mathrm{ORS})=1.51-2.52)$. However, few differences in risk were observed based on the timing of first exposure. After conducting 20 tests of association, only three significant differences in risk were observed based on the timing of exposure; these results suggested an elevated risk of behaviour disorder among youth first exposed to any type of interpersonal violence during adolescence $(\mathrm{OR}=2.37,95 \% \mathrm{Cl}$ 1.69-3.34), especially being beaten by another person $(\mathrm{OR}=2.44 ; 95 \% \mathrm{Cl} 1.57-3.79)$, and an elevated risk of substance use disorder among youth beaten by someone during adolescence $(\mathrm{OR}=2.77,95 \% \mathrm{Cl}$ 1.94-3.96).

\section{Conclusions}

Children exposed to interpersonal violence had an elevated risk of psychiatric disorder. However, age at first episode of exposure was largely unassociated with psychopathology risk.

\section{Declaration of interest}

None.

\section{Copyright and usage}

(c) The Royal College of Psychiatrists 2017.
Childhood adversity is a strong determinant of psychopathology, estimated to at least double the risk for both youth- and adultonset disorders. ${ }^{1-3}$ However, it remains unclear whether there are developmental stages when a first episode of adversity has the most impact on risk for psychopathology. Determining whether there may be 'sensitive periods' ${ }^{4,5}$ when experience, including exposure to adversity, imparts enduring effects could provide new insight into the mechanisms underlying risk for psychopathology. It could also help determine the optimal timing of interventions, as childhood spans multiple developmental periods when different types of interventions, including homeor school-based programmes, could be deployed to minimise the effects of adversity based on the age of the child.

Although the developmental timing of child interpersonal violence could influence subsequent psychopathology risk, ${ }^{6,7}$ there is little agreement as to whether earlier or later exposure is more harmful. Early interpersonal violence could be more damaging than later interpersonal violence because it occurs when foundational neural circuits are developing that provide the scaffolding for more complex abilities. ${ }^{8,9}$ Further, early violence exposure could also compromise a child's ability to master early developmental tasks, such as emotion regulation and the formation of secure attachments, creating a negative developmental cascade that influences future developmental tasks. ${ }^{10,11}$ Alternatively, later interpersonal violence could be more harmful than earlier violence exposure because adolescents have developed the cognitive skills to conceptualise experiences of interpersonal violence and their meaning. ${ }^{12-15}$
The brain also undergoes substantial structural and functional change during adolescence. ${ }^{16}$

Among the few empirical studies examining the time-dependent effects of interpersonal violence, no consensus has emerged regarding the developmental periods associated with greatest risk for psychopathology following exposure to abuse. Both prospective $^{17-19}$ and retrospective studies ${ }^{20,21}$ have found that earlier interpersonal violence (before age 5 or before age $12^{22-24}$ ) is more strongly associated with depression than exposure during later developmental periods. However, one retrospective study ${ }^{25}$ and two prospective studies found interpersonal violence occurring later in childhood (age 10-12) ${ }^{26}$ or adolescence (age 12-17) ${ }^{27}$ was more harmful than abuse that occurred earlier. Three prospective studies $^{7,28,29}$ and two retrospective studies ${ }^{30,31}$ found no developmental timing differences. Mixed results have also been observed for the role of developmental timing of child interpersonal violence on post-traumatic stress disorder (PTSD), ${ }^{19,24,32,33}$ substance misuse ${ }^{34-36}$ and other mental-health related outcomes. ${ }^{17,28}$ These mixed results could be because of methodological differences across studies. For example, prior research includes a mix of epidemiological $v$. non-epidemiological samples. Prior studies have also used both administrative records and interview-based self-report to collect information about interpersonal violence exposure, as well as both symptom and diagnostic measures to determine psychopathology.

In the current study, we analysed data from the National Comorbidity Survey Replication - Adolescent Supplement 
(NCS-A), the largest nationally representative study of the prevalence and correlates of DSM-IV mental disorders among English-speaking US adolescents. Our objective was to examine whether variation in the timing of a first episode of childhood interpersonal violence was a determinant of disorder-specific risk for psychopathology onset. By studying adolescents, we minimised potential bias due to retrospective recall relative to studies conducted in adults. Moreover, by conducting these analyses in an epidemiological sample, we had sufficient power to conduct within-group analyses (i.e. among those exposed to interpersonal violence) and could obtain generalisable results.

\section{Method}

\section{Sample and procedures}

The NCS-A conducted face-to-face surveys on 10148 adolescents between ages 13 and 18 from the continental USA. Respondents were sampled through a dual-frame sample comprised of adolescents from households in the National Comorbidity Survey Replication (NCS-R $)^{37} \quad(n=904)$ and adolescents from a representative sample of schools in the adult sample areas of the NCS-R ( $n=9244$ across 320 schools). Data were collected in the adolescent's home between February 2001 and January 2004 using laptop-assisted personal interviews. The overall response rate was $75.6 \%$ (85.9\% household sample; $74.7 \%$ school sample). ${ }^{38}$ Parent written informed consent and adolescent written informed assent were obtained prior to interview completion. The Human Subjects Committees of Harvard Medical School and the University of Michigan approved NCS-A study recruitment and informed consent procedures. We analysed data from adolescents with valid sampling weights and complete data on all variables $(n=9948$, $98.03 \%$ of the total sample). Adolescents included in our analytic sample $(n=9948)$ did not differ from those who were excluded $(n=200)$ with respect to age, ethnicity, gender and poverty level. However, the excluded sample comprised more adolescents from families living in rural areas $(23.1 \% v .14 .8 \%, P=0.05)$ and with less than a high school education $(26.6 \% v .15 .4 \%, P<0.01)$

\section{Measures}

\section{Psychiatric disorders}

To determine whether adolescents met lifetime DSM-IV diagnostic criteria for a psychiatric disorder, trained lay interviewers administered (to adolescents) a modified version of the World Health Organization Composite International Diagnostic Interview (CIDI) ${ }^{39}$ The CIDI is a fully structured diagnostic interview designed to generate psychiatric diagnoses from the DSM-IV and the ICD-10. ${ }^{39}$ The NCS-A version of the CIDI was slightly modified from the version used in the NCS-R to be developmentally appropriate for youth. ${ }^{40}$ Building from the results of a factor analysis of the NCS-A data, ${ }^{41}$ we examined four empirically defined disorder clusters: distress disorders (major depressive disorder, dysthymia, generalised anxiety disorder, PTSD, and separation anxiety disorder), fear disorders (panic disorder with or without agoraphobia, agoraphobia without panic disorder, social phobia, and specific phobia), behaviour disorders (attention-deficit hyperactivity disorder (ADHD), oppositional defiant disorder (ODD), conduct disorder, and eating disorders, i.e. anorexia nervosa, bulimia nervosa, and binge-eating behaviour); and substance use disorders (alcohol misuse with or without dependence, and drug misuse with or without dependence). These four disorder clusters are a parsimonious representation of psychopathology and account for the significant comorbidity within and between disorders.
Parents ( $n=8485,83.61 \%$ of the total sample of adolescents) also completed a self-administered questionnaire designed to ascertain data on four child disorders where prior studies have found parent reports are important for making these diagnoses: ${ }^{42}$ depression/dysthymia, ADHD, ODD and conduct disorder. For these disorders, an 'or' criterion was applied, whereby adolescents were classified as meeting diagnostic criteria for the disorder if it was reported by either the child or parent. Agreement between parent and child reports was excellent for depression $(\kappa=0.80$, 95\% CI 0.77-0.83) and varied for externalising disorders (ADHD $\kappa=0.35,95 \%$ CI $0.29-0.40$; ODD $\kappa=0.48,95 \%$ CI $0.45-0.51$, conduct disorder $\kappa=0.60,95 \%$ CI $0.55-0.65$ ).

Age at onset of each disorder was assessed using question probes shown in a prior study to increase recall accuracy among adults. ${ }^{43}$ For the four disorders where combined child and parent data were used, age at onset reported by parents was used or, when missing, the age at onset reported by the child. Overall, there was good agreement in age at onset between parent and child reports (mean difference 0.83 years $($ s.d.) $=0.57$ ). Agreement between parent and child reports was excellent for depression $(r=0.92)$ and varied for externalising disorders (ADHD $r=0.21$; ODD $r=0.86$; conduct disorder $r=0.49$, all $P<0.05$ ).

\section{Predictors: exposure to childhood interpersonal violence}

Lifetime exposure to interpersonal violence was ascertained in the PTSD screener section of the CIDI. Adolescents reported whether they had experienced any of the four types of interpersonal violence: (a) beaten by parents: 'badly beaten up by your parents or the people who raised you'; (b) beaten by other person: 'badly beaten up by anyone else'; (c) rape: 'someone either having sexual intercourse with you or penetrating your body with a finger or object when you did not want them to, either by threatening you or by using force', and (d) sexual assault/molestation: 'other than rape, ever sexually assaulted or molested'. Interviewers were instructed to query children about these events when they were alone. Age at first exposure to each event was assessed using the same question probes (as the diagnoses) to increase recall accuracy.

\section{Covariates}

In all models, we adjusted for the following covariates: age (continuous), highest level of parent education (less than high school, high school, some college, or college graduate - referent), poverty index ratio, which was derived based on family size and the ratio of family income to the family's poverty threshold $(\leqslant 1.5$, low income; $>1.5-3$, low-middle income; $>3-\leqslant 6$, high-middle income; and $>6$, high income - referent), ethnicity (non-Hispanic White - referent, non-Hispanic Black, Hispanic; other), region of the country (Northeast, Midwest - referent, South, West), and urbanicity (major metropolitan area, other urbanised area, rural area - referent). We also adjusted for any psychiatric disorder occurring prior to or at the same time as the focal disorder under investigation, as described in detail below. We stratified analyses by gender, given that the prevalence of interpersonal violence ${ }^{44}$ and psychopathology ${ }^{45,46}$ vary between males and females.

\section{Statistical analysis}

Consistent with prior NCA-analyses, ${ }^{2,47}$ we created time-varying outcome variables, which indicated the presence or absence of any disorder within the disorder cluster (see online supplement DS1). For each outcome, we first conducted discrete-time survival analyses using logistic regression ${ }^{48}$ to estimate the association 
between exposure to each type of interpersonal violence (coded as $0=$ non-exposed and $1=$ exposed) and the odds for at least one disorder within the disorder cluster (model 1). We then tested the association between first exposure to interpersonal violence categorised into three different time periods and the disorder cluster (model 2). In these models, age at first exposure was coded through a set of time-varying indicators used in previous studies $^{19,20,49}$ to denote three developmental periods: 1 , early childhood, ages $0-5 ; 2$, middle childhood, ages $6-10$; and 3 , adolescence, ages 11-18. For this time-varying exposure variable, person-years prior to first exposure were coded as 0 . Thereafter, for adolescents reporting exposure, adversity was coded as 1,2 or 3 in the year of first exposure and in all subsequent personyears. Thus, the reference group for each analysis was based on a different denominator, corresponding to anyone who was unexposed during the current or prior developmental period. For model 2, a test of homogeneity (d.f. $=2$ ) was used to evaluate whether the beta coefficients (indicating the effect of age at first exposure relative to never exposed) for the three developmental periods were significantly different from each other. This homogeneity test can be thought of as a test for statistical interaction between exposure ( 0 , unexposed; 1 , exposed) and developmental period (1, early childhood; 2 , middle childhood 3 , adolescence). Within each exposure, these tests of homogeneity were Bonferroni corrected $(\alpha=0.05 / 5=0.01)$ to account for testing for outcomes. In cases where the null hypothesis was rejected (two-sided $P<0.01$ ), we conducted post hoc Tukey-corrected tests to evaluate, after adjustment for multiple testing, how the effect of exposure differed by developmental period. These Tukey tests were adjusted for all pairwise comparisons. All analyses were conducted using the survey regression procedures in SAS Version 9.4 to account for the complex survey design.

\section{Results}

\section{Exposure to interpersonal violence: prevalence and age at first exposure}

Descriptive and bivariate results are reported in Table 1. The sample was diverse, although predominately White (65.7\%), was comprised of roughly equal numbers of males and females, and included a large proportion of adolescents whose families were college educated $(35.6 \%)$, high income $(34.5 \%)$, and living in metropolitan areas $(47.5 \%)$. In the bivariate analyses, exposure to any interpersonal violence was more common among females (12.2\% v. 8.6\%; $P<0.001)$ and less common among adolescents whose parents had a college degree $(8.9 \%$ among children of college graduates $v \cdot 10.6-12.0 \%$ among children of parents with less than a college degree) (Table 1). No differences were found in the prevalence of exposure to any interpersonal violence based on ethnicity, parental income, or place of residence.

Being beaten by other person was the most commonly reported type of interpersonal violence $(4.9 \%, n=469)$, followed by sexual assault/molestation $(3.6 \%, n=329)$, rape $(2.3 \%$, $n=252)$ and being beaten by parents $(1.8 \%, n=162)$ (Table 2). Most youth were first exposed to interpersonal violence during adolescence. For example, among the $10.4 \%$ of youth exposed to any interpersonal violence, $1.5 \%$ were first exposed in early childhood, $3.1 \%$ in middle childhood and $5.8 \%$ during adolescence.

Youth exposed to one type of violence were somewhat more likely to report being exposed to a second type. Specifically, the correlations for exposure ranged from $r=0.19$ for being beaten by other person and sexual assault/molestation to $r=0.70$ for rape and sexual assault/molestation. Correlations for the timing of first exposure ranged from 0.15 for being beaten by other person and sexual assault/molestation to 0.68 for rape and sexual assault/molestation.

Gender differences were observed in the reporting of exposure to interpersonal violence (Table 3). Girls were more likely than boys to report exposure to all types of interpersonal violence except being beaten by other person.

Exposure to any interpersonal violence was also more commonly reported among older adolescents, defined as those aged 16-18, compared with younger adolescents, defined as those aged $13-15$ (13.3\% v. 8.1\% respectively; see online Table DS1). We examined whether recency effects may have potentially introduced bias in reports of adversity by examining whether older were more likely than younger adolescents to report being first exposed during adolescence. Overall, the reported age at first exposure to interpersonal violence did not vary based on the adolescent's current age (online Table DS1). Although gender differences were observed $(P<0.01)$, these differences were small in magnitude (early childhood first exposure: $0.5 \%$ male; $1 \%$ female; middle childhood: $1.3 \%$ male; $1.8 \%$ female; and adolescence: $2.7 \%$ male and $3.1 \%$ female).

\section{Sensitive periods for the effect of interpersonal violence on psychopathology}

As reported elsewhere, ${ }^{50}$ psychiatric disorders were common and the prevalences of these disorder classes were patterned by gender, age, ethnicity and family socioeconomic status (online Table DS2). For instance, girls reported more fear disorders $(32.7 \%$ v. $25.7 \%$, $P<0.001)$ and distress disorders $(29.4 \%$ v. $17.7 \%, P<0.001)$, whereas boys reported more behaviour disorders $(34.3 \% v$. $27.7 \%, P<0.001)$ and substance use disorders $(12.5 \%$ v. $10.2 \%$, $P=0.01)$. Additionally, distress and substance use disorders were reported less frequently by younger adolescents $(P<0.001)$

Exposure to interpersonal violence was associated with a higher odds for nearly all types of psychiatric disorders (Table 4; online Table DS3). For example, exposure to any interpersonal violence increased the odds for a fear disorder by a factor of 1.73, after adjusting for covariates. The largest association observed was for exposure to sexual assault/molestation and the odds for any distress disorder ( $\mathrm{OR}=2.52$; 95\% CI 1.83-3.46).

As indicated by the $P$-values for the test of homogeneity, three significant differences $(P<0.05)$ were observed indicating variation in the magnitude of association between interpersonal violence and psychiatric disorders based on age at first exposure. First, we found that the effect estimate for any exposure during adolescence $v$. unexposed on behaviour disorder $(\mathrm{OR}=2.37)$ was $40 \%$ larger than the effect observed for exposure during middle childhood $v$. unexposed $(\mathrm{OR}=1.46)$. Second, these results appeared driven by exposure to being beaten by other person, which was more strongly associated with the risk of a behaviour disorder during adolescence $(\mathrm{OR}=2.44)$ than in early or middle childhood ( $\mathrm{OR}=0.80$ and 1.07 , Tukey-corrected $P<0.05)$. Third, exposure to being beaten by someone was more strongly associated with the risk for substance use disorder during adolescence than it was during early childhood $(\mathrm{OR}=2.77 v$. 0.75, Tukey-corrected $P<0.05$ ).

Although exposure to interpersonal violence was associated with a higher odds for all types of psychiatric disorder classes in both males and females, there were no significant differences among males or among females in the developmental timing of exposure to interpersonal violence (all homogeneity $P>0.05$; see online Table DS4).

We also conducted secondary analyses on depression, the most commonly studied outcome of interpersonal violence, to facilitate 


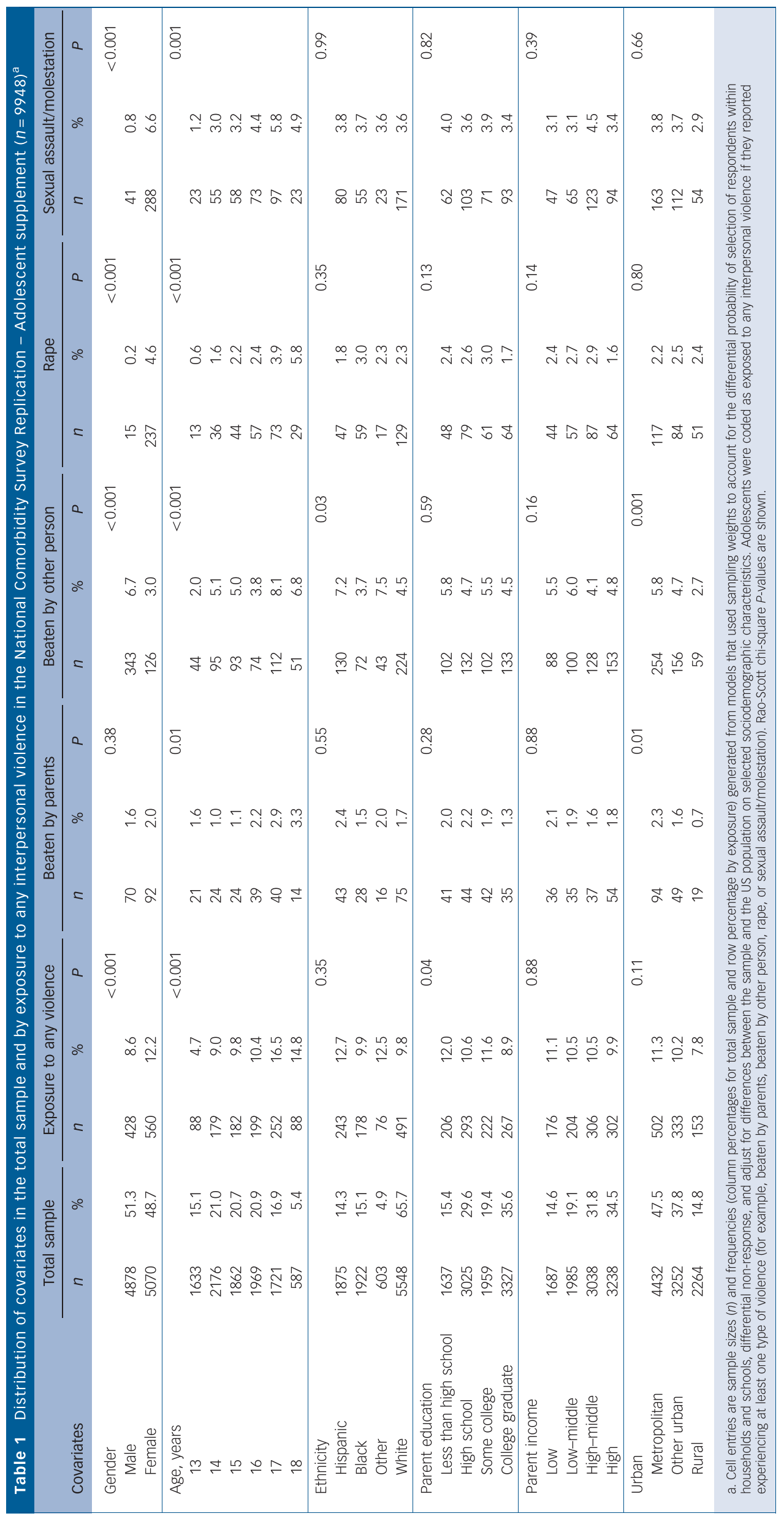




\begin{tabular}{|c|c|c|c|}
\hline Exposure to interpersonal violence & $n$ & $\%$ & $P$ \\
\hline Any interpersonal violence & 988 & 10.4 & $<0.001$ \\
\hline Early childhood & 142 & 1.5 & \\
\hline Middle childhood & 280 & 3.1 & \\
\hline Adolescence & 566 & 5.8 & \\
\hline Beaten by parents & 162 & 1.8 & 0.78 \\
\hline Early childhood & 58 & 0.7 & \\
\hline Middle childhood & 68 & 0.8 & \\
\hline Adolescence & 36 & 0.4 & \\
\hline Beaten by other person & 469 & 4.9 & $<0.001$ \\
\hline Early childhood & 14 & 0.1 & \\
\hline Middle childhood & 118 & 1.3 & \\
\hline Adolescence & 337 & 3.4 & \\
\hline Rape & 252 & 2.3 & $<0.001$ \\
\hline Early childhood & 39 & 0.3 & \\
\hline Middle childhood & 57 & 0.5 & \\
\hline Adolescence & 156 & 1.5 & \\
\hline Sexual assault/molestation & 329 & 3.6 & $<0.001$ \\
\hline Early childhood & 51 & 0.6 & \\
\hline Middle childhood & 90 & 1.1 & \\
\hline Adolescence & 188 & 2.0 & \\
\hline \multicolumn{4}{|c|}{$\begin{array}{l}\text { a. Cell entries are sample sizes ( } n \text { ) and frequencies (percentages) generated from } \\
\text { models that used sampling weights to account for the differential probability of } \\
\text { selection of respondents within households and schools, differential non-response } \\
\text { and adjust for differences between the same and the US population on selected } \\
\text { sociodemographic characteristics. Adolescents were coded as exposed ( } v \text {. unexposed) } \\
\text { for any interpersonal violence and each type of interpersonal violence. Rao-Scott } \\
\text { chi-square } P \text {-values are shown. }\end{array}$} \\
\hline
\end{tabular}

comparisons with prior studies. Exposure to any interpersonal violence was associated with a higher odds for depression in the total sample (see online Table DS5) and gender-stratified analyses (see online Table DS6). No significant differences emerged based on developmental timing of exposure to interpersonal violence on depression (all homogeneity $P>0.05$ ).

\section{Discussion}

These data do not support the view that there are sensitive periods shaping risk for psychiatric disorder among adolescents following exposure to interpersonal violence. Although adolescents who were maltreated had, on average, about twice the risk of having an onset of a psychiatric disorder, age at first episode of exposure to interpersonal violence was generally not associated with the magnitude of increased risk. Several previous prospective $e^{7,28,30}$ and retrospective studies ${ }^{30,31}$ in much smaller samples of youth have also not found evidence for sensitive periods. The lack of identified sensitive periods here and elsewhere could be because interpersonal violence disrupts multiple developmental processes, including attention and emotion regulation, which each could have overlapping influences on psychopathology. ${ }^{10,11}$ Thus, there may be differentially sensitive periods for each of these developmental processes, ${ }^{51}$ but not a single sensitive period when exposure to violence increases susceptibility to psychiatric disorders defined through symptom-level measures.

Although by and large there was little evidence to support the primary hypothesis that there were sensitive periods, we did observe three instances in which the developmental timing of exposure to adversity appeared to matter. First, youth exposed to any type of interpersonal violence during adolescence had an increased risk of experiencing a behaviour disorder relative to youth first exposed in middle childhood. Second, the effect of any interpersonal violence on behaviour disorders appeared primarily driven by being beaten by other person (i.e. who was not a parent), as youth first exposed in adolescence to this type of violence had an elevated risk of behaviour disorder relative to youth first exposed during middle childhood. Third, being beaten by another person during adolescence also elevated risk of substance use disorder relative to exposures that first occurred during the earliest stage of development. These findings are consistent with some, ${ }^{17}$ although not all, ${ }^{27,30}$ studies examining the effects of timing of childhood interpersonal violence on these outcomes in adolescents. To our knowledge, no studies have assessed the effect of developmental timing of exposure to adversity in relation to subsequent eating disorders.

Interpersonal violence during adolescence may exert disorderspecific effects on behaviour and substance use disorders for several reasons. In addition to more advanced cognitive abilities ${ }^{14,15}$ and brain-related changes that occur during adolescence, ${ }^{16}$ adolescent-onset interpersonal violence could more often result in behavioural manifestations of psychopathology relative to earlier-onset interpersonal violence exposure. Previous research indicates that the prevalence of conduct disorder increases with age, at least up to 16 years of age, ${ }^{52}$ and that the diagnosis of eating disorders in children under 10 is rare ${ }^{53}$ Moreover, recent work also suggests that for some cognitive and affective capacities, the time of greatest sensitivity to the environment is during adolescence. $^{49,54-57}$

\section{Strengths and limitations}

The current study had several strengths. We conducted these analyses in a large population-based sample of adolescents, enabling us to generate nationally representative estimates of disorder-specific effects, reduce the likelihood of retrospective recall bias relative to studies conducted in adults, and capture a larger proportion of maltreated youth relative to studies examining administrative records. Unlike prior NCS-A studies, we included data from youth whose parents did not participate.

\begin{tabular}{|c|c|c|c|c|c|c|c|}
\hline \multirow[b]{2}{*}{ Exposure } & \multicolumn{2}{|c|}{ Total sample $(n=9948)$} & \multicolumn{2}{|c|}{ Males $(n=4878)$} & \multicolumn{2}{|c|}{ Females $(n=5070)$} & \multirow[b]{2}{*}{$P$} \\
\hline & $n$ & $\%$ & $n$ & $\%$ & $n$ & $\%$ & \\
\hline Any interpersonal violence & 988 & 10.4 & 428 & 4.4 & 560 & 6.0 & $<0.001$ \\
\hline Beaten by parents & 162 & 1.8 & 70 & 0.8 & 92 & 1.0 & 0.38 \\
\hline Beaten by other person & 469 & 4.9 & 343 & 3.5 & 126 & 1.5 & $<0.001$ \\
\hline Rape & 252 & 2.3 & 15 & 0.1 & 237 & 2.2 & $<0.001$ \\
\hline Sexual assault/molestation & 329 & 3.6 & 41 & 0.4 & 288 & 3.2 & $<0.001$ \\
\hline
\end{tabular}




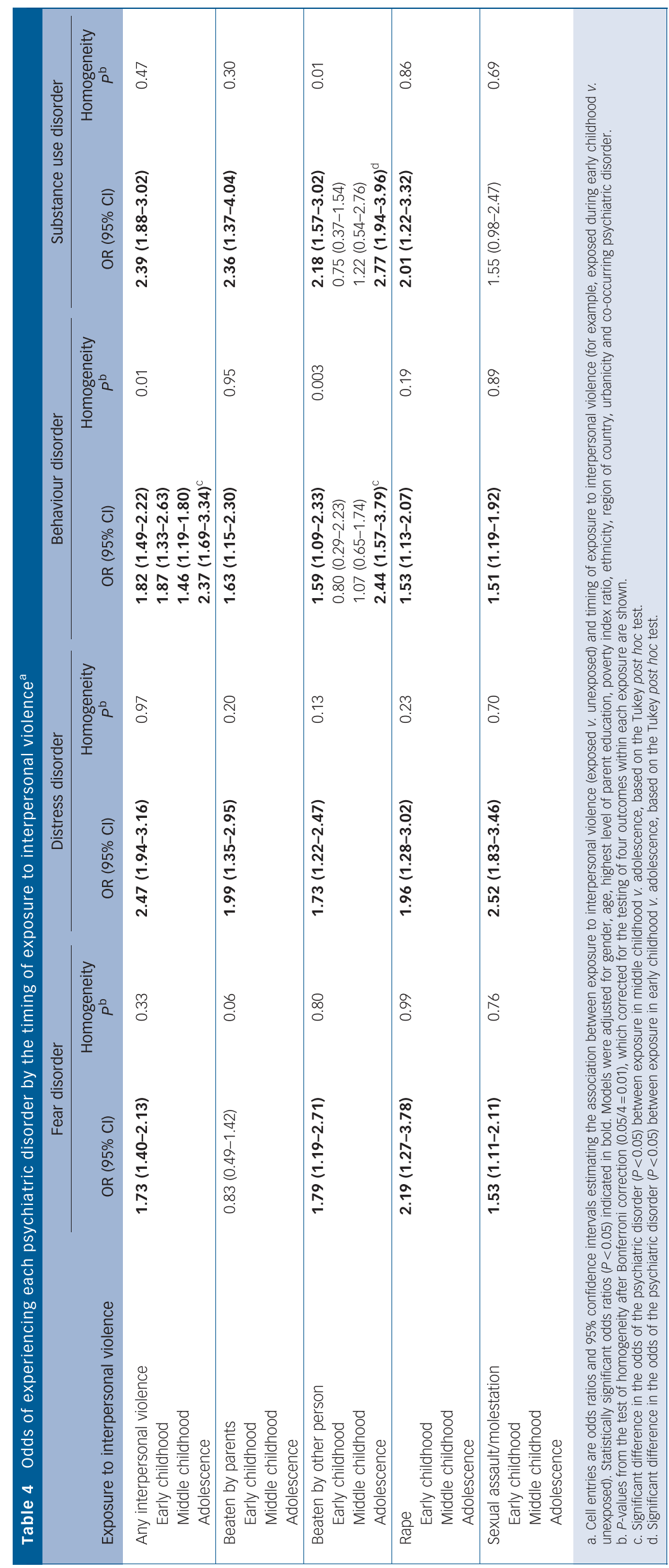


Some forms of violence were more common among youth without parent-reported data. We also considered exposures individually, rather than simultaneously, ${ }^{58}$ in order to guide intervention planning and understand interpersonal violence-specific associations to risk for psychiatric disorder.

However, several limitations should be noted. First, exposure to interpersonal violence, meaning its occurrence and age at first exposure, were assessed retrospectively. Retrospective reports of interpersonal violence may be less reliable and valid than prospective reports, because of memory inaccuracies, a reluctance to disclose personal matters, or current mood states. ${ }^{59}$ However, a major strength of our study is that the recollection period to recall experiences of interpersonal violence exposure was brief, as adolescents were recalling their exposures during earlier childhood. Further, specific question probes were used to increase recall accuracy with respect to age at first exposure to these forms of interpersonal violence. Prospective research is needed to replicate these findings. This prospective work should incorporate repeated measures of trauma exposure and mental health in order to differentiate short- $v$. long-term effects of trauma timing on psychopathology. Important to note, even if such reporting biases were present in our study, retrospective and prospective measures produce similar estimates of association with mental disorders, ${ }^{60}$ suggesting that trauma exposure is harmful regardless of ascertainment strategy.

Second, the interpersonal violence measure did not capture information about its severity, chronicity, or duration. Thus, for the three associations where sensitive periods were observed, we are unable to discern whether these developmental timing effects persisted after accounting for these other features of the adversity, which could have possibly inflated these observed associations. These adversity characteristics should be included in future studies to disentangle their contribution to the possible effects of age at first exposure. Related to this, because of the small number of cases of adolescents with behaviour disorders, we were unable to evaluate the age at first exposure to violence on specific types of behaviour disorders. Finally, our results for adolescent first exposure may be misleading, as not everyone in the sample was old enough to have contributed data for the full exposure period. Studies in older adolescents or young adults can help illuminate the importance of both child- and adolescent-onset exposure to interpersonal violence.

\section{Implications}

In conclusion, our results suggest that, irrespective of the age at first exposure to violence and the type of interpersonal violence, exposure to violence more than doubled the odds of having a psychiatric disorder. However, age at first episode of exposure appears largely unassociated with psychopathology risk. If sensitive periods for psychopathology do exist, they may not be apparent during adolescence or easily identified through symptom-level measures. Ongoing work to investigate sensitive periods, especially in population-based samples, can help determine whether there are developmental stages when adversity has a more enduring impact. Insights from this work could inform clinical and prevention efforts by suggesting the age stages when interventions are most able to prevent the onset of mental health disorders and when public health expenditures can yield greater returns on investment.

\section{Funding}

Research reported in this publication was supported by the National Institute of Menta Health of the National Institutes of Health under Award Number K01MH102403 (E.C.D.), R01MH103291 and R01MH106482 (K.A.M.) and the Intramural Research Program of the Eunice Kennedy Shriver National Institute of Child Health and Human Development. The content is solely the responsibility of the authors and does not necessarily represent the official views of the National Institutes of Health.

\section{Acknowledgements}

The authors thank Jenna Kiely, Emily Moya and Kristen Nishimi for their assistance in preparing this manuscript for publication.

Erin C. Dunn, SCD, MPH, Psychiatric and Neurodevelopmental Genetics Unit, Massachusetts General Hospital, Boston, Department of Psychiatry, Harvard Medical School, Boston and Stanley Center for Psychiatric Research, The Broad Institute of Harvard and MIT, Cambridge, Massachusetts; Yan Wang, PhD, MPH, Psychiatric and Neurodevelopmental Genetics Unit, Massachusetts General Hospital, Boston, Massachusetts; Jenny Tse, BA, Department of Epidemiology, Harvard T.H. Chan Massachusetts; Jenny Tse, BA, Department of Epidemiology, Harvard T.H. Chan
School of Public Health, Boston, Massachusetts; Katie A. McLaughlin, PhD, Department of Psychology, University of Washington, Seattle, Washington;

Garrett Fitzmaurice, PhD, Department of Psychiatry, Harvard Medical School, McLean Hospital, Laboratory for Psychiatric Biostatistics, Belmont and Department of Biostatistics, Harvard T.H. Chan School of Public Health, Boston, Massachusetts; Stephen E. Gilman, SCD, Department of Epidemiology and Department of Social and Behavioral Sciences, Harvard T.H. Chan School of Public Health and Health Behavio Branch, Division of Intramural Population Health Research, Eunice Kennedy Shriver National Institute of Child Health and Human Development, Rockville, Maryland; Ezra S. Susser, MD, DrPH, Department of Epidemiology, Mailman School of Public Health, Columbia University, New York and New York State Psychiatric Institute, New York, USA

Correspondence: Erin C. Dunn, SCD, MPH, Psychiatric and Neurodevelopmenta Genetics Unit, Center for Genomic Medicine, Massachusetts General Hospital, 185 Cambridge Street, Simches Research Building Sixth Floor, Boston, MA 02114, USA. Email: dunnreprints@gmail.com

First received 14 Feb 2017, final revision 9 Aug 2017, accepted 17 Aug 2017

\section{References}

1 McLaughlin KA, Green JG, Gruber MJ, Gruber MJ, Sampson NA, et al. Childhood adversities and adult psychiatric disorders in the National Comorbidity Survey Replication II: associations with persistence of DSM-IV disorders. Arch Gen Psychiatry 2010; 67: 124-32.

2 McLaughlin KA, Green JG, Gruber MJ, Sampson NA, Zaslavsky AM, Kessler RC. Childhood adversities and first onset of psychiatric disorders in a national sample of US adolescents. JAMA Psychiatry 2012; 69: 1151-60.

3 Norman RE, Byambaa M, De R, Butchart A, Scott J, Vos T. The long-term health consequences of child physical abuse, emotional abuse, and neglect: a systematic review and meta-analysis. PLOS Med 2012; 9: e1001349.

4 Knudsen E. Sensitive periods in the development of the brain and behavior. J Cogn Neurosci 2004; 16: 1412-25.

5 Bornstein $\mathrm{MH}$. Sensitive periods in development: structural characteristics and causal interpretations. Psychol Bull 1989; 105: 179-97.

6 Barnett D, Manly JT, Cicchetti D. Defining child maltreatment: the interface between policy and research. In Child Abuse, Child Development, and Social Policy (eds D Cicchetti, SL Toth): 7-73. Ablex, 1993.

7 English DJ, Graham JC, Litrownik AJ, Everson M, Bangdiwala SI. Defining maltreatment chronicity: are there differences in child outcomes. Child Abuse Negl 2005; 29: 575-95.

8 McLaughlin KA, Sheridan MA, Nelson CA. Neglect as a violation of speciesexpectant experience: neurodevelopmental consequences. Biol Psychiatry 2017; 82: 462-71.

9 McLaughlin KA, Sheridan MA, Lambert HK. Childhood adversity and neura development: deprivation and threat as distinct dimensions of early experience. Neurosci Biobehav Rev 2014; 47: 578-91.

10 Cicchetti D, Toth SL. A developmental psychopathology perspective on child abuse and neglect. J Am Acad Child Adolesc Psychiatry 1995; 34: 541-65.

11 Cicchetti D. Socioemotional, personality, and biological development: illustrations from a multilevel developmental psychopathology perspective on child maltreatment. Annu Rev Psychol 2016; 67: 187-211.

12 Quas JA, Goodman GS, Jones DP. Predictors of attributions of self-blame and internalizing behavior problems in sexually abused children. J Child Psychol Psychiatry 2003; 44: 723-36.

13 Compas BE, Connor-Smith JK, Saltzman H, Thomsen AH, Wadsworth ME. Coping with stress during childhood and adolescence: problems, progress, and potential in theory and research. Psychol Bull 2001; 127: 87-127.

14 Maccoby EE. Social-emotional development and response to stressors. In Stress, Coping, and Development in Children (eds M Rutter, N Garmezy): 217-34. McGraw-Hill, 1983 
15 Garbarino J. Troubled youth, troubled families: the dynamics of adolescent maltreatment. In Child Maltreatment: Theory and Research on the Causes and Consequences of Child Abuse and Neglect (eds D Cicchetti, V Carlson): 685-706. Cambridge University Press, 1989.

16 Stroud LR, Foster EM, Papandonatos GD, Handwerger K, Granger DA, Kivlighan KT, et al. Stress response and the adolescent transition: performance versus peer rejection stressors. Dev Psychopathol 2009; 21: 47-68.

17 Thornberry TP, Henry KL, Ireland TO, Smith CA. The causal impact of childhood-limited maltreatment and adolescent maltreatment on early adult adjustment. J Adolesc Health 2010; 46: 359-65.

18 Keiley MK, Howe TR, Dodge KA, Bates JE, Petti GS. The timing of child physical maltreatment: a cross-domain growth analysis of impact on adolescent externalizing and internalizing problems. Dev Psychopathol 2001; 13: 891-912.

19 Kaplow JB, Widom CS. Age of onset of child maltreatment predicts long-term mental health outcomes. J Abnorm Psychol 2007; 116: 176-87.

20 Dunn EC, McLaughlin KA, Slopen N, Rosand J, Smoller JW. Developmental timing of child maltreatment and symptoms of depression and suicidal ideation in young adulthood: results from the National Longitudinal Study of Adolescent Health. Depress Anxiety 2013; 30: 955-64.

21 Dunn EC, Nishimi K, Lott AP, Bradley B. Is developmental timing of trauma exposure associated with depressive and post-traumatic stress disorder symptoms in adulthood? J Psych Res 2017; 84: 119-127.

22 Maercker A, Michael T, Fehm L, Becker ES, Margraf J. Age of traumatisation as a predictor of post-traumatic stress disorder or major depression in young women. Br J Psychiatry 2004; 184: 482-7.

23 Mccutcheon WV, Heath AC, Nelson EC, Bucholz KK, Madden PA, Martin NG et al. Accumulation of trauma over time and risk for depression in a twin sample. Psychol Med 2009; 39: 431-41.

24 Schoedl AF, costa MC, Mari JJ, Mello MF, Tyrka AR, Carpenter LL, et al. The clinical correlates of reported childhood sexual abuse: an association between age at trauma onset and severity of depression and PTSD in adults. J Child Sex Abus 2010; 19: 156-70.

25 Khan A, McCormack HC, Bolger EA, McGreenery CE, Vitaliano G, Polcari A et al. Childhood maltreatment, depression, and suicidal ideation: critical importance of parental and peer emotional abuse during developmental sensitive periods in males and females. Front Psychiatry 2015; 6: 42.

26 Harpur $\mathrm{L}$, Polek E, van Harmelen AL. The role of timing of maltreatment and child intelligence in pathways to low symptoms of depression and anxiety in adolescence. Child Abuse Negl 2015; 47: 24-37.

27 Thornberry TP, Ireland TO, Smith CA. The importance of timing: the varying impact of childhood and adolescent maltreatment on multiple problem outcomes. Dev Psychopathol 2001; 13: 957-79.

28 Jaffee SR, Maikovich-Fong AK. Effects of chronic maltreatment and maltreatment timing on children's behavior and cognitive abilities. J Child Psychol Psychiatry 2011; 52: 184-94.

29 Oldehinkel AJ, Ormel J, Verhulst FC, Nederhof E. Childhood adversities and adolescent depression: a matter of both risk and resilience. Dev Psychopathol 2014; 26: 1067-75.

30 Manly JT, Kim JE, Rogosch FA, Cicchetti D. Dimensions of child maltreatment and children's adjustment: contributions of developmental timing and subtype. Dev Psychopathol 2001; 13: 759-82.

31 Pietrek $C$, Elbert $T$, Weierstall $R$, Müller $O$, Rockstroh B. Childhood adversities in relation to psychiatric disorders. Psychiatry Res 2013; 206: 103-10.

32 Glod CA, Teicher MH. Relationship between early abuse, posttraumatic stress disorder, and activity levels in prepubertal children. $J$ Am Acad Child Adolesc Psychiatry 1996; 35: 1384-93.

33 McCutcheon VV, Sartor CE, Pommer NE, Bucholz KK, Nelson EC, Madden PA et al. Age at trauma exposure and PTSD risk in young adult women. $J$ Trauma Stress 2010; 23: 811-4.

34 Estaugh V, Power C. Family disruption in early life and drinking in young adulthood. Alcohol Alcohol 1991; 26: 639-44.

35 Freeman RC, Collier K, Parillo KM. Early life sexual abuse as a risk factor for crack cocaine use in a sample of community-recruited women at high risk for illicit drug use. Am J Drug Alcohol Abuse 2002; 28: 109-31.

36 Spak L, Spak F, Allebeck P. Sexual abuse and alcoholism in a female population. Addiction 1998; 93: 1365-73.

37 Kessler RC, Merikangas KR. The national comorbidity survey replication (NCS-R): background and aims. Int J Methods Psychiatr Res 2004; 13: 60-8.
38 Kessler RC, Avenevoli S, Costello EJ, Green JG, Gruber MJ, Heeringa S, et al. National comorbidity survey replication adolescent supplement (NCS-A): II. Overview and design. J Am Acad Child Adolesc Psychiatry 2009; 48: 380-5.

39 Wittchen HU. Reliability and validity studies of the WHO-Composite International Diagnostic Interview (CIDI): a critical review. J Psychiatr Res 1994; 28: 57-84

40 Merikangas KR, Avenevoli S, Costello EJ, Koretz D, Kessler RC. National comorbidity survey replication adolescent supplement (NCS-A): 1. Background and measures. J Am Acad Child Adolesc Psychiatry 2009; 48: 367-79.

41 Kessler RC, Avenevoli S, McLaughlin KA, Green JG, Lakoma MD, Petukhova M. Lifetime co-morbidity of DSM-IV disorders in the US National Comorbidity Survey Replication Adolescent Supplement (NCS-A). Psychol Med 2012; 42 1997-2010.

42 De Los Reyes A, Kazdin AE. Informant discrepancies in the assessment of childhood psychopathology: A critical review, theoretical framework, and recommendations for further study. Psychol Bull 2005; 131: 483-509.

43 Knauper B, Cannell CF, Schwarz N, Bruce ML, Kessler RC. Improving the accuracy of major depression age of onset reports in the US National Comorbidity Survey. Int J Methods Psychiatr Res 1999; 8: 39-48.

44 Koenen KC, Roberts AL, Stone DM, Dunn EC. The epidemiology of early childhood trauma. In The Impact of Early Life Trauma on Health and Disease: The Hidden Epidemic (eds R Lanius, E Vermetten): 13-24. Cambridge University Press, 2010

45 Dunn EC, Gilman SE, Willett JB, Slopen NB, Molnar BE. The impact of exposure to interpersonal violence on gender differences in adolescent-onset major depression: results from the National Comorbidity Survey Replication (NCS-R). Depress Anxiety 2012; 29: 392-9.

46 Gaub M, Carlson CL. Gender differences in ADHD: a meta-analysis and critical review. J Am Acad Child Adolesc Psychiatry 1997; 36: 1036-45

47 Green JG, McLaughlin KA, Berglund PA, Gruber MJ, Sampson NA, Zaslavsky AM, et al. Childhood adversities and adult psychiatric disorders in the National Comorbidity Survey Replication I: associations with first onset of DSM-IV disorders. Arch Gen Psychiatry 2010; 67: 113-23.

48 Singer JD, Willett JB. Applied Longitudinal Data Analysis: Modeling Change and Event Occurrence. Oxford University Press, 2003.

49 Andersen SL, Tomada A, Vincow ES, Valente E, Polcari A, Teicher MH. Preliminary evidence for sensitive periods in the effect of childhood sexual abuse on regional brain development. J Neuropsychiatry Clin Neurosci 2008 20: 292-301.

50 Kessler RC, Avenevoli S, Costello EJ, Georgiades K, Green JG, Gruber MJ, et al. Prevalence, persistence, and sociodemographic correlates of DSM-IV disorders in the National Comorbidity Survey Replication Adolescent Supplement. Arch Gen Psychiatry 2012; 69: 372-80.

51 Dunn EC, Busso DS, Raffeld M, Smoller JW, Nelson CA, Doyle AE, et al. Does developmental timing of exposure to child maltreatment predict memory performance in adulthood? Results from a large, population-based sample Child Abuse Neglect 2016; 51: 181-91.

52 Maughan B, Rowe R, Messer J, Goodman R, Meltzer H. Conduct disorder and oppositional defiant disorder in a national sample: developmental epidemiology. J Child Psychol Psychiatry 2004; 45: 609-21.

53 Bryant-Waugh RJ, Lask BD, Shafran RL, Fosson AR. Do doctors recognise eating disorders in children? Arch Dis Child 1992; 67: 103.

54 Blakemore SJ. Development of the social brain in adolescence. $J R$ Soc Med 2012; 105: 111-6.

55 Blakemore SJ, Choudhury S. Development of the adolescent brain implications for executive function and social cognition. J Child Psychology Psychiatry 2006; 47: 296-312.

56 Casey BJ, Jones RM. Neurobiology of the adolescent brain and behavior: implications for substance use disorders. J Am Acad Child Adolesc Psychiatry 2010; 49: 1189-201.

57 Somerville LH, Casey BJ. Developmental neurobiology of cognitive control and motivational systems. Curr Opin Neurobiol 2010; 20: 236-41.

58 Marshall AD. Developmental timing of trauma exposure relative to puberty and the nature of psychopathology among adolescent girls. J Am Acad Child Adolesc Psychiatry 2016; 55: 25-32.

59 Hardt J, Rutter M. Validity of adult retrospective reports of adverse childhood experiences: review of the evidence. J Child Psychol Psychiatry 2004; 45 260-73

60 Scott KM, McLaughlin KA, Smith DAR, Ellis PM. Childhood maltreatment and DSM-IV adult mental disorders: comparison of prospective and retrospective findings. Br J Psychiatry 2012; 200: 469-75. 